\title{
LESSONS LEARNED FROM WORKING WITH RURAL FARM WOMEN ON MIDDELPOS FARM, SWARTLAND MUNICIPALITY, WEST COAST, WESTERN CAPE.
}

\author{
Ingrid Lestrade ${ }^{1}$ Orcid ID: 0000-0001-5551-1498
}

I have a vision of creating an alternate rural economy that does things differently and gets better results.

To put it into context, I live on an isolated farm which is part of a land reform programme. I often wish the digital world would create something that would help women specifically, who are trying to farm, to get information.

I must agree that there are some encouraging signs that this is beginning to happen.

Recently I was asked by the IDC to provide them with a social benefit map, because the direction that many of the state entities are taking, is that they don't only want to give money, but they also want to see the social benefit of their investments, rather than simply the profitability factor.

But quickly the question arises: How do you provide that kind of map with the limited capabilities that you have? After all, most of the women I work with can't read or write and many have never seen the inside of a school.

This is one area where digital tools can make a big difference.

Women in this land reform space will only be taken seriously if they have the tools to present their ideas. If you produce a wonderful document that includes a social map, a marketing plan, and all the various elements you need in order to satisfy the people you are talking to - once it looks good - people treat you differently.

The digital world can play a massive role in helping women to get into the agri-space and become successful. For example, the Western Cape Government provided seeds to poor families to farm and grow their own vegetables on one hectare. But those families had no idea how to measure one hectare of land.

There are apps that can measure a piece of land and that will help you answer a basic question: How big is your land? This is too much for them to imagine or visualise. So we asked the Department of Rural Development to take an aerial photo to indicate the scale and area that we are planting. Once we got to the point where the women could see the farm, it started to make sense and they could plan accordingly.

Because we sit with this kind of problem, we suspect a lot of others are also having the same problems. Our experiences are not unique.

One of the things that a university can do to help, is to look for practical solutions which will help women to enter into the farming space with success.

Too often we have to spend hours on Google searching through all kinds of information, just to find one simple solution. In addition, some of the areas have bad connectivity and therefore you can't really rely on Facebook or Whatsapp either.

It's so important to simplify via digital media. Once you start using big words, it scares people off rather than to bring them closer together. Simple, practical solutions are what gets people to participate.

One must be able to centralize information that is available to farmers like myself and who are unable to drive all over the place. We should be able to put information on a screen or in the cloud so that women can participate. 
This will bring together a larger group of people who have personally never met anyone to help, but now they can talk digitally and interact with people and get guidance.

Right now the information that is available and the policies are so far away from the reality on the ground. It's too advanced most of the time. The questions that we as farmers are asking are very simple: How many vegetables can I plant on a hectare? What is the maximum potential of this soil? What organic products are out there?

No doubt we are underusing this digital media in agriculture and in the NGO space. I have an app for identifying plants that I don't know. I take a picture and the app names the plant. You must see the reactions of these women when I show this to them. None of this is rocket science, but it's still very underused in terms of what it can do for people who are isolated and far away from academics.

Let's develop specific tools for specific areas and fields. Digital developers need to get to know women farmers and their specific needs much better, in order to address these problems.

It's no secret that the farming space in this country is held by men. There are not many women who make it. How wonderful it is for a farm like ours to see women who are trying to further their education and livelihoods, e.g. when they are using an app to get info and they tell you that an olive tree takes a certain amount of water.

That's the power of digital access.

We can make a dent in poverty when we bring brilliant minds together to think about how we can go forward, and if we share the realities of ordinary people. 